\title{
In memoriam: Boris Dubrovin
}

\section{Vladimir B. Matveev ${ }^{1} \cdot$ Michel Semenov-Tian-Shansky ${ }^{1}$}

Published online: 25 April 2019

(c) Springer Nature B.V. 2019

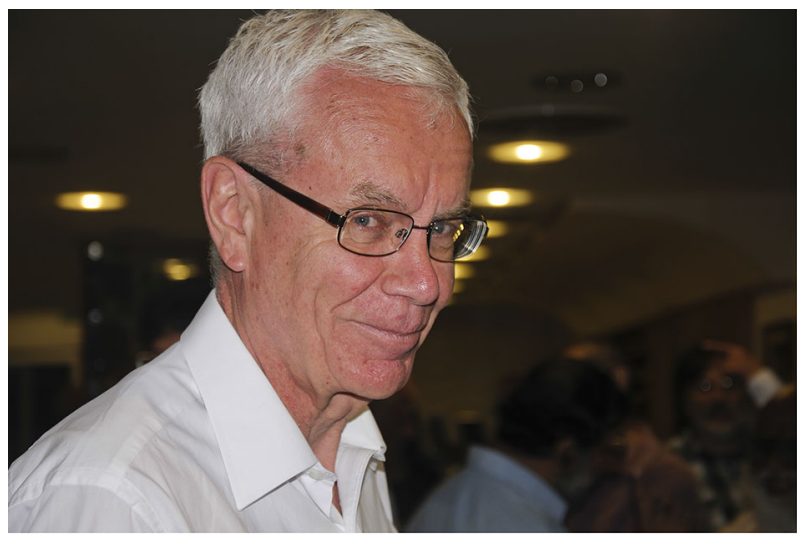

Boris Dubrovin (1950-2019)

The mathematical community has suffered a big loss with the passing of Professor Boris Dubrovin on March 19th in Trieste after his courageous battle against a rare and terrible disease (ALS). He started to serve on the editorial board of LMP in 2009, and was a very dedicated and efficient editor.

Boris started his scientific career in the 70's at Moscow University as a PhD student of Professor S.P. Novikov; his initial background was in Algebraic Topology, but since he quickly became one of the key actors in the newly emerging theory of integrable systems. His contribution to the study of finite-band solutions of the KdV equation was honored by the Prize for young mathematicians of the Moscow Mathematical Society which he received in 1976 (together with A. Its and I. Krichever). He also made important contributions to the theory of isomonodromic deformations of ordinary differential equations with applications ranging from conformal field theory to the theory of strings. Around the late 80's and early 90's he started to develop the theory of Frobenius manifolds, a notion that rapidly became one of the focal points of

Vladimir B. Matveev

Vladimir.Matveev@u-bourgogne.fr

1 Université de Bourgogne, Dijon, France 
Modern Mathematical Physics, with numerous applications in the theory of Integrable Systems, Superstring theory, and Quantum Cohomology. In 1988, Boris became a full Professor of Moscow University. His 3-volume book on Modern Geometry (written in collaboration with S.P. Novikov and A.T. Fomenko) turned into a reference text for several generations of students worldwide. In 1993, he was elected Distinguished Professor of Mathematical Physics at SISSA, and Trieste became the main center of his research and teaching activities for a quarter of a century. For several years, he also has been a director of the Mathematical Physics Group at SISSA. Since 2010, Boris was the Director and organizer of the new Bogolyubov Laboratory Geometrical methods in Mathematical Physics of Moscow University. This Laboratory has become one of the most active mathematical centers in Moscow. Finally, let us mention that he has been an invited speaker in prestigious international conferences, including ICMP (Swansea 1988, Rio 2006), ICM (Berlin 1998), and ECM (Budapest 1996).

He continued his work up to the last months of his life; one of his very last papers appeared in Duke Mathematical Journal a few days before his death. Boris' legacy will inspire Mathematical Physicists for many years to come.

Dijon

March 29, 2019

Publisher's Note Springer Nature remains neutral with regard to jurisdictional claims in published maps and institutional affiliations. 